\title{
O PRIMEIRO SÉCULO DO PORTUGUÂE ESCRITO
}

\author{
Ana Maria Martins
}

Universidade de Lisboa

\section{INTRODUÇÃO: FACTOS PRINCIPAIS E REFERÊNCIAS}

O presente artigo é uma versão da comunicação que apresentei no colóquio Na nosa lyngoage galega. A emerxencia do galego como lingua escrita na Idade Media no final de Novembro de 2005, em Santiago de Compostela. Embora se ocupe das manifestações iniciais do português escrito, e não do galego escrito, enquadra-se no tema do colóquio na medida em que a construção, peça a peça, de um cenário hispânico para a época em apreço permitirá compreender melhor as circunstâncias em que emergiram as produções escritas tanto do galego como de cada uma das restantes línguas ibéricas. Uma vez que o colóquio acolheu também comunicações tendo por foco as áreas catalã, aragonesa, leonesa e castelhana, uma parte das peças necessárias fica disponível (em forma actualizada) para futuras experiências de articulação.

Num artigo recente, Ivo Castro (2004b) faz o ponto da situação do conhecimento sobre "a primitiva produção escrita em português", identificando os contributos recentes mas também os mais precoces (com destaque para Pedro de Azevedo, Leite de Vasconcelos, Lindley Cintra e Avelino de Jesus da Costa) nos quais se alicerça o actual saber sobre o assunto. A existência deste artigo de Ivo Castro oferece-me a possibilidade de não recontar uma história que eu contaria menos bem. Limitar-me-ei então a registar alguns factos essenciais e encaminharei depois o artigo num sentido mais reflexivo que descritivo. O leitor desapontado não será deixado sem melhor opção.

O português escrito é observável a partir da segunda metade do século XII (Martins 1999, 2001a 2001b, 2004; Castro, Marquilhas e Albino 2001; Castro 2004a, 2004b; Souto Cabo 2003a, 2003b, 2004a, 2004b), sendo os mais antigos textos que o atestam a Notícia de Fiadores de Paio Soares Romeu, a anotação de despesas de Pedro Parada, e o Pacto entre Gomes Pais e Rami- 
ro Pais, o primeiro datado de 1175 , os dois últimos não datados mas presumivelmente próximos de $1175^{1}$. Esta cronologia para a emergência do português escrito não é consensual, é a que eu própria tenho por boa. O pomo de discórdia está na atribuição, ou não, da qualidade de escritos em português a certos textos. António Emiliano (2003c; cf. Emiliano e Pedro 2004) rejeita a classificação como portugueses dos textos da segunda metade do século XII (vd. apêndice no final deste artigo), considerando a Notícia de Torto, de cerca de 1214, o texto mais antigo escrito em português. Ramón Lorenzo, por sua vez, considera a Notícia de Torto "un documento híbrido latino-portugués, con dominio de la lengua romance en un estado incipiente" (2003: 161). Por fim, José António Souto Cabo retém como marco cronológico para a emergência do português escrito a segunda metade do século XII, mas retira do conjunto de três textos que apontei a Notícia de Fiadores (Souto Cabo 2003a) e a anotação de despesas de Pedro Parada (cf. Souto Cabo 2004a: 588). Feitas as contas, apenas Ivo Castro parece não divergir do que anteriormente defendi e aqui mantenho, considerando textos afins a Notícia de

1. Souto Cabo (2003a) propõe para o Pacto a data provável de 1173. A hipótese apoia-se, primeiramente, no facto de o Pacto estar escrito do lado da carne de um pergaminho que acolhe, do lado do pelo, um contrato de compra e venda datado de 1175 (sem relação visível com o Pacto) e, secundariamente, na validade de dois anos estipulada para o Pacto no texto que o consigna. Como normalmente não se escreveria do lado do pelo tendo disponível o lado, melhor, da carne (cf. Guerra 2003), é legítima a dedução de que a feitura do Pacto precedeu a do documento datado de 1175, ao qual coube, por exclusão, o lado do pelo. Já o segundo passo do raciocínio que suporta a datação hipotética de 1173 me parece extremamente frágil por supor o recurso a um processo de reciclagem de pergaminhos para o qual não existe evidência no contexto relevante (o dos documentos notariais particulares). Note-se que o caso em discussão é diferente quer do da Notícia de Torto, que ocupa sozinha as duas faces do suporte de escrita, quer do da Notícia de Fiadores que revela o aproveitamento, na esfera familiar, das zonas livres de um pergaminho pertencente à família dos Paiva (cf. Martins 1999). Quanto ao Pacto, conforme notou Ivo Castro (2004b: 96), parece fundamental a observação de que, do lado da carne, o pergaminho foi preparado para receber duas cópias de um documento partido por ABC (pelo que o regramento, inverso, de cada uma das metades não ocupa o espaço central), não tendo sido, contudo, concluída a tarefa projectada. Na verdade, só uma das partes do pergaminho veio a ser ocupada pela cópia única do Pacto que hoje conhecemos. Isto sugere que o contrato entre Gomes Pais e Ramiro Pais foi suspenso antes mesmo de estar formalizado. Terá sido essa suspensão (inesperada e, com certeza, inconveniente) do trabalho que um notário começara a executar que terá levado o mesmo notário a re-utilizar o pergaminho para um outro fim. Neste cenário alternativo, a re-utilização do pergaminho terá sido imediata, do que decorre que o Pacto terá sido escrito no mesmo ano que o documento de compra e venda com o qual partilha o suporte, isto é, em 1175. A favor desta hipótese está o facto de o pergaminho apresentar sinais de um único processo de dobragem, executado no sentido de proteger o documento de compra e venda (cf. Souto Cabo 2003a: 352, Guerra 2003: 409). Visto que a dobragem era feita logo que concluída a fase de escrita (cf. Guerra 2003), se o Pacto tivesse existido solitariamente durante o suposto período de dois anos em que teria validade jurídica, esperar-se-ia que se observassem marcas de uma primitiva dobragem, executada por forma a proteger o lado da carne do pergaminho, ou seja, o Pacto. 
Torto, a Notícia de Fiadores, o Pacto entre Ramiro Pais e Gomes Pais, e outros, que conjuntamente tenho por textos escritos em português.

Para o período que medeia entre 1175 e 1255 (data dos dois mais antigos documentos em português produzidos na chancelaria do rei Afonso III), estão identificados cerca de 30 textos escritos em português, conforme mostra o apêndice colocado no final do presente artigo. De novo, a constituição deste universo de três dezenas de documentos não é consensual por envolver dois factores susceptíveis de gerar dissonâncias: a avaliação do carácter português (ou ainda latino-português) da escrita dos textos relevantes e o estabelecimento de datações aproximadas para os documentos, em largo número, que não estão datados.

Embora o mais antigo documento régio escrito em português seja o testamento de D. Afonso II, de 1214, é o ano de 1255, em tempo de D. Afonso III, que assinala o re-aparecimento dos textos escritos em português no âmbito da chancelaria régia ${ }^{2}$. Ivo Castro (1991, 2004a, 2004b) elege-a como marco cronológico para estabelecer o limite final da fase mais antiga da produção escrita em português: "antes de 1255 existiu também uma diminuta produção primitiva em português, constituída por documentos de carácter notarial escritos em português".

Em 1279, ao iniciar o seu reinado, D. Dinis torna geral o uso da escrita portuguesa na chancelaria régia. Apesar desta oficialização do português como língua escrita, só na última década do século XIII a produção documental particular em português cresce significativamente, tornando-se dominante relativamente à latina já no século seguinte ${ }^{3}$.

2. O que significa apenas que os documentos régios escritos em português que, seguramente, foram produzidos entre 1214 e 1255 não sobreviveram, tal como aconteceu com os que terão existido antes de 1214, conforme salienta Ivo Castro (2004b: 81): "bastaria examinar os dados internos dos documentos datados de 1214 para se perceber que eles não tinham sido os únicos, nem certamente os primeiros, a usar o português como língua da escrita antes de 1255 " (cf. Castro 1991: 183).

3. A produção escrita em português que chegou até nós deixa de ser ocasional a partir do final da década de 60, aumentando desde então de forma continuada e gradual, como mostrou Souto Cabo (2002) ao observar a documentação particular no período de 1256 a 1285. É também no final da década de 60 que ganha uma clara dinâmica ascendente a produção de documentos escritos em português na chancelaria de Afonso III. No entanto, só na década de 90 os documentos particulares escritos em português se tornarão abundantes ao ponto de na viragem do século passarem a ser maioritários face à produção escrita em latim. (Para o ano de 1285, Souto Cabo (2002) localiza não mais que 27 documentos escritos em português num conjunto de 38 cartórios monásticos). Como ilustração do crescimento acentuado do português escrito entre $1290 \mathrm{e}$ 1299, veja-se como o mosteiro de Chelas originou 27 documentos escritos em português, na região de Lisboa, entre 1290 e 1299, face a apenas 10 até 1289. No mosteiro de São Miguel de Vilarinho a razão é de 10 documentos, produzidos entre 1290 e 1299, para 4 documentos até então (cf. Martins 2001b). 
Voltando um pouco atrás, à fronteira cronológica de 1255, importa destacar que antes dessa data dispomos apenas de um documento régio (o Testamento de D. Afonso II, de 1214), sendo todos os restantes documentos particulares. Em 1999 observei que o conjunto dos documentos particulares escritos em português (antes de 1255) que então se conhecia era constituído por documentos "identificáveis como notícias, fintos e testamentos" (1999: 499). Esta observação não foi abalada pelo posterior aparecimento de novos textos, pois genericamente enquadram-se nos mesmos géneros (cf. Souto Cabo 2004a: 583). A investigação que Susana Pedro tem desenvolvido sobre o género noticia permite hoje afirmar que os documentos particulares escritos em português até 1255 se restringem na verdade a dois géneros, o testamento e a notícia, ou talvez apenas um, a notícia.

A notícia é um género diplomático específico que tem por fim registar informalmente determinados factos e elementos com o fim de preservar a sua memória. Com efeito verifica-se a associação próxima da notícia a uma lista, a um inventário, logo desde os primeiros exemplos conhecidos. A Notitia Dignitatum, nome pelo qual é conhecido este importantíssimo documento para o estudo da organização militar do Império Romano, cujo original terá sido redigido entre 395 e 425, comporta de facto duas notícias, que listam os cargos oficiais e administrativos do Império do Oriente e do Ocidente. Similarmente, a Notitia Galliarum, datável do século v, lista as 17 províncias e 115 cidades das Gálias no Império Romano tardio.

Conhecem-se, para o território hispânico, diversos documentos em suporte original ou copiados em diplomas e cartulários, que se intitulam "notitia", "noticia", "nodicia", "notitia uel inuentarium", etc. Refiram-se as célebres Nodicia de Kesos, do século x, de Leão, e a Noticia de Torto, do século xiII, do Norte de Portugal O..

Na linha destes dados, embora não exaustivos, tudo parece apontar para uma identificação de conteúdo entre a 'notícia' e uma lista ou inventário, que pode ser de variadíssimas coisas: oficiais do exército imperial romano, queijos consumidos num mosteiro, arras, fiadores, dívidas, etc. Ora os documentos que se têm publicado como "finto", "nómina", "escrito", "relação", "inventário", "anotação", de acordo com o termo patente no próprio documento ou inferido pelos editores, correspondem exactamente à definição de notícia como registo de factos ou itens quantificáveis. Têm em comum serem listas, não obedecerem a um discurso diplomático rígido, por consistirem tipicamente de narrativas ou elencos, e com escatocolo quase sempre inexistente ou resumido à menção da data num número muito reduzido de casos.

Em minha opinião estamos perante um único tipo documental, que abarca eventos (como a Noticia de Torto), listas de itens contáveis (como a Notitia Digni- 
tatum ou a Nodicia de Kesos) e memórias de actos jurídicos anteriores, que podem ou não ter sido materializados por escrito. A este último grupo podem pertencer os testamentos (ou 'mandas') não-datados e não-validados (que, noutra perspectiva, não são senão listas de disposições), mesmo aqueles que não ostentam o termo "noticia de manda" O...

É neste sentido que, em meu entender, se deve pôr de lado a ideia tradicional de que uma 'notícia', tal como foi repetidamente referido a propósito da Noticia de Torto, é um documento preparatório, uma minuta ou rascunho de um hipotético mundum perdido. É, sim, um documento final que não obedece, pelas próprias características do género diplomático, às normas aplicáveis aos documentos dispositivos" (Pedro 2004: 73-75).

Durante o período que nos ocupa o português escrito não se encontrava limitado à esfera da produção notarial. Sendo hoje geralmente aceite que a arte poética dos trovadores se constituiu desde sempre em tradição escrita, circulando não em suporte de oralidade e memória mas em "folhas" soltas depois reunidas em cancioneiros individuais e em grandes compilações colectivas, parece não haver margem para duvidar de que havia produção literária escrita em português desde a segunda metade do século xII. A partir de meados do século xIII, a produção literária alargar-se-á à prosa, tendo sido D. Afonso III o introdutor em Portugal do romance de cavalaria do ciclo do Graal (cfr. Castro 1983, 1984, 1988, 1993). Se os textos literários são, em geral, deixados fora dos debates sobre os textos mais antigos escritos em português, tal deve-se ao facto de nos terem chegado através de manuscritos posteriores (ou muito posteriores) ao momento de produção dos originais. Mas talvez seja possível mostrar que há cópias merecedoras dos textos originais, conforme sugere Ivo Castro (2004b) e discutiremos mais adiante.

As mesmas técnicas minuciosas de observação e de reconstituição de procedimentos de escrita que ajudam o linguista a extrair o máximo de informação desses textos [notariais] podem ser postas ao serviço, com excelentes resultados, de textos de natureza não documental, os globalmente chamados textos literários, os quais existem normalmente em cópias e não em autógrafos, se integram em estemas genealógicos enigmáticos e são ricos em problemas de autoria, datação, local de produção e dependência de fontes ou exemplares. Estas dificuldades do texto literário costumam limitar o seu emprego como documento linguístico, mas quando peritagens codicológicas, por exemplo, determinam as circunstâncias exactas da produção de um determinado suporte textual, então nada impede que ele seja tomado como documento linguístico, com o benefício de estar livre de formularismos e de oferecer instâncias muito variadas e expansivas da linguagem da época (Castro 2004b: 71). 


\section{DOIS TIPOS DE ESCRITA NOS TEXTOS NÃO-LITERÁRIOS}

Em trabalho anterior, ao comparar a escrita portuguesa das duas versões do Testamento de D. Afonso II, de 1214, com a escrita portuguesa dos documentos particulares anteriores a 1255 , considerei estar perante dois tipos de escrita (ou duas escritas portuguesas, no sentido de duas famílias de escritas) - cf. Martins (1999). A escrita do Testamento do rei Afonso II, que persistirá para além do século xIII, apresenta-se inovadora e estabilizada, sendo um produto (elaborado) da chancelaria régia; comparativamente, a escrita dos documentos particulares, que não sobreviverá ao primeiro século do português escrito, é conservadora e pluriforme. Continuo a pensar que esta distinção entre escrita portuguesa inovadora e escrita portuguesa conservadora (a que hoje talvez preferisse chamar 'escrita marginal, tendencialmente conservadora') não é ficcional e é útil, não devendo ser ignorada nem quando se avalia se um texto antigo está ou não escrito em português nem quando se utiliza o mesmo texto como fonte de conhecimento linguístico (sobretudo fonológico). Nos dois quadros que apresento seguidamente procuro esclarecer como pode ser identificada cada uma das escritas portuguesas. O Quadro 2 é integralmente dedicado à identificação das características principais da escrita portuguesa conservadora.

Quadro 1: DuAs ESCRITAS PORTUGUESAS NO PRIMEIRO SÉCULO DA PRODUর̃̃ O ESCRITA

ESCRITA PORTUGUESA CONSERVADORA

Caracterizada por um espectro muito largo de variação gráfica e pela persistência de opções gráficas latinizantes, que convivem com outras claramente romances. Parte das opções gráficas que contempla virão a ser abandonadas.
ESCRITA PORTUGUESA INOVADORA

Apresenta-se depurada de vestígios anacrónicos da tradição latino-notarial e mostra ter-se constituído através de um processo de selecção entre variantes gráficas que traduziam diferentes soluções para a representação de segmentos fonológicos não latinos.

É uma escrita claramente alfabética à qual são estranhas, em geral, quer as formas de representação logográfica quer as formas de representação "trácica". supra-segmental (logográfica); na vertente mai criativa, apresenta processos de representacão sensíveis a propriedades sub-segmentais ("escrita trácica", nos termos de Marquilhas 2004).

Os textos em escrita portuguesa conservadora admitem muito limitadamente (em comparação com os textos latino-portugueses) léxico latino sem continuidade no português.

Os textos em escrita portuguesa conservadora apresentam uma sintaxe portuguesa (portanto, não articulada com um sistema de flexão casual, ainda que se considere a morfologia casual empobrecida das variedades tardias do latim).
Os textos em escrita portuguesa inovadora excluem o léxico latino sem continuidade no português. (Naturalmente, palavras latinas poderão ocorrer em fórmulas, expressões ou termos pertencentes à linguagem jurídica).

Os textos em escrita portuguesa inovadora partilham com os textos em escrita portuguesa inovadora uma sintaxe claramente portuguesa. 
Quadro 2: TRAÇOS PRINCIPAIS DA ESCRITA PORTUGUESA CONSERVADORA ESCRITA PORTUGUESA CONSERVADORA (CA. 1175 - CA. 1275)

Tracos

Exemplos

1. Elementos latinizantes

1.1. Presença, em grau muito reduzido, de léxico latino sem continuidade no português.

alia (NT)*, existis (NT), exieritis (Pacto), ut (Pacto), hec (Notícia de haver), uxor (Finto dos casais de Lijó), sicut (Finto de Rodrigo Nunes)

*NT = Notícia de Torto

1.2. Algumas formas gráficas latinas representam globalmente (ou seja, de forma logográfica) palavras portuguesas. Tendencialmente, as formas latinas pertencem a um conjunto limitado que integra muitas palavras gramaticais. illo/illos/illa (Notícia de haver, NT, Pacto), ego (Pacto), suo/suos (NT, Pacto), ipso (NT), ille 'lhe' (NT), super (NT), hic 'i' (NT), ad (Notícia de haver), aut 'ou' (Carta de Benfeita) quomodo (Pacto), abet (Pacto), habeo (manda de Dona Fruilhe), fuerint (Nómina), fuerunt (Dívidas de Pedro Martins), sedeat (Notícia de haver), dedit (Despesas de Pedro Parada), teneat (Manda de Dona Fruilhe), mater (NT), pater (NT), hodie (Pacto)

1.3. Ocorrem segmentos gráficos que não têm um contraponto sonoro ("letras mudas"), como é o caso de $<l>$ entre vogais, $<\mathrm{e}>$ final em palavras terminadas em consoante, e $<\mathrm{t}>$ final nas formas verbais de terceira pessoa. Estes segmentos gráficos são motivados etimologicamente.

(i) quales (NT), casales (NT), pelagio, (NT, N. Fiadores, Pacto), pelaiz (N. Fiadores, Pacto); uelasco (Pacto)

(ii) fece (NT), feze (NT), quale (NT, Pacto), pane (NT), male (Notícia de Fiadores), gomenze (Pacto) (iii) fecit (Notícia de Fiadores), intret, uenit (Pacto), tenet (Notícia de haver), debet (Nómina)

2. Traços criativos (cf. Marquilhas 2004)

2.1. As grafias nem sempre espelham as oposições fonológicas baseadas no traço de vozeamento. Ou abate (NT), petroso (Finto de Lijó), toto (Pacto), cecar 'cegar' (NT), amico (Pacto), gaualeiros (Pacseja o traço [+/- voz] é abstraído no plano gráfico. to), trico (Manda de Mendo Ermigues), fíidos 'vindos' (NT) fice 'vez' (NT), deuenda 'defenda' / defender (Notícia de haver)

2.2. As grafias $<\mathrm{i}>,<\mathrm{u}>$ podem representar as vogais /e/, /o/ quer em posição átona quer em posição tónica. Ou seja, <i>, <u> representam, respectivamente, as classes [- bx, - rec] e [- bx, + arr] Cf. Marquilhas (2004), Cintra (1987: 51-52), Maia (1986: 351, 391-394), Mariño Paz (1998: 99-100), Souto Cabo (2004b: 367).

2.3. A nasalidade vocálica pode não ter expressão gráfica qualquer que seja o contexto em que a vogal ocorre.

secuda 'segunda' (despesas de Pedro Parada), partia 'partam' (Notícia de Fiadores), grade 'grande' (Pacto)

3. Traços não redutíveis à oposição 'latinizante'/"criativo'

3.1. Acentuada variação gráfica na representação dos ditongos decrescentes (sobretudo ou, ei). O polimorfismo decorre da existência de múltiplas representações para a semivogal (que pode não ter contrapartida gráfica) mas também, em menor grau, de diferentes representações para a vogal. Este traço em associação com o traço identificado em 2.2. leva a que $<i>$ possa representar o ditongo ei.

Laurenzo/Lourenzo (NT), mauro/mouro (Notícia de haver), fillou/fillau (Notícia de dívidas de Pedro Fafiaz), arauca 'Arouca' (Partição de Mor Martins), custov (NT) octra (NT), octorgou (Partição de Mor Martins), oc 'ou' (Partição de Mor Martins), mandoc 'mandou' (NT), otra (NT) mando 'mandou' (NT), obs 'ous = aos' (Testamento de Sancha Martins), nugeira, múreira (Manda de Margarida Garcia), figueyredo, ulueyra (Testamento de Sancha Martins), plecto (NT), lecxasem (NT) rec (NT), lec- 


Traços ESCRITA PORTUGUESA CONSERVADORA (CA. 1175-CA. 1275)

to (Manda de Dona Fruilhe), malfegtoria (Manda de Dona Fruilhe), lexarem (NT), getarum (NT), qera (Manda de Margarida Garcia), freres (Partição de Mor Martins), Figeerecdo (NT), lito 'leito', diritu 'direito' (Manda de Margarida Garcia), muita (NT), multas (NT), fructu (NT)

3.2. Diferentes representações gráficas para a consoante africada palatal surda, nomeadamente $\langle\mathrm{g}\rangle$, agou 'achou' (NT) ius 'chus' (Manda de Mendo Ermigues), iau 'chão', iumaco (Manda de Margarida Garcia), chamua (Carta de Benfeita), chumazo (Testamento de Aldora Afonso), chiarneca, chião (Finto de Rodrigo Nunes), culcia 'colcha' (Manda de Margarida Garcia), plus 'chus' (NT), plomaço (Testamento de Aldora Afonso)

3.3. Não sendo <ch> uma grafia 'especializada' na representação da consoante africada palatal surda (cf. 3.2), este dígrafo pode igualmente representar a consoante africada dental surda e as consoantes oclusivas velares surda e sonora.

3.4. A consoante fricativa palatal surda pode ser representada por $\langle\mathrm{x}\rangle$ ou $\langle$ s $>$.

lecxasem (NT), laxo (Nómina), pesotas 'peixotas' (Notícia de haver), riselus 'reixelos', leisu (Manda de Margarida Martins)

3.5. A consoante fricativa palatal sonora (com oribeiso 'beijou' (NT) gem em $S$ latino) pode ser representada por $\langle\mathrm{S}\rangle$, gunchauiz 'Gonçalves', manchelos, chumacho, urachum 'oração', lamecho 'Lamego' (Manda de Dona Fruilhe), archa (Notícia de haver) exibindo uma grafia 'autónoma' relativamente às que representam a consoante africada palatal sonora (i.e. $\langle\mathrm{i}\rangle,\langle\mathrm{g}\rangle,\langle\mathrm{gi}\rangle$ ).

Os traços apontados no quadro 2 não aparecem globalmente em cada um dos textos representativos da escrita portuguesa conservadora. Os "elementos latinizantes" estão normalmente presentes, a par de algum dos "traços criativos" e de alguns dos restantes traços. A extensão dos textos é um factor relevante neste domínio, assim como o carácter mais ou menos geral dos próprios traços considerados. Num pequeno texto, como a Notícia de Fiadores, pode não ocorrer algum dos traços latinizantes, o que não é esperável num texto mais longo. De facto, na Notícia de Fiadores não ocorre léxico latino sem continuidade no português. A indistinção gráfica entre consoantes que se opõem apenas pela propriedade de [+/- vozeadas] é um traço que se manifesta na maior parte dos textos, enquanto o uso de $<\mathrm{u}>/<\mathrm{i}>$ para representar quer a vogal alta $(/ \mathrm{u} /-/ \mathrm{i} /)$ quer a vogal média $(/ \mathrm{O} /-/ \mathrm{e} /)$, por exemplo, tem um âmbito mais restrito no universo de textos considerado.

Dos traços registados no quadro 2 , a escrita portuguesa inovadora retém de forma atenuada os identificados em 2.1 e 2.3 (ambos "traços criativos"). Quanto a 2.3, nos textos em escrita portuguesa inovadora, as vogais em hiato continuam a apresentar a possibilidade de não ter marcada graficamente a 
nasalidade vocálica; quanto a 2.1, só as consoantes sibilantes podem escapar, no plano gráfico, à marcação da distinção de vozeamento (como acontece, no ms. L do Testamento de D. Afonso II, no que diz respeito à africada dental surda, enquanto no manuscrito T a distinção é sistematicamente observada). Os restantes traços apontados no quadro 2 estão, em geral, ausentes dos textos em escrita portuguesa inovadora. Não deve surpeender, no entanto, que sendo as duas escritas portuguesas coetâneas, uma ou outra característica gráfica tipicamente pertencente à escrita conservadora se estenda ocasionalmente a um texto da outra família (ou vice-versa). Assim, por exemplo, num documento do mosteiro da Pendorada, datado de 1277, aparecem as formas leysen 'leixem', cobsa 'cousa', que isoladas num texto sem outros traços "conservadores" não põem em causa a filiação do texto na família da escrita portuguesa inovadora (cf. Martins 2001b: 128-129). Noutros casos, a convivência entre as duas escritas portuguesas, que partilharam o mesmo espaço geográfico durante o primeiro século do português escrito, originou resultados mais híbridos, tornando certos documentos produzidos neste período (talvez sobretudo depois de 1255) de difícil classificação. Exemplo disso são alguns dos textos, de 1256-1269, editados por Souto Cabo (2004b) para os quais não parece possível estabelecer uma filiação simples, na escrita portuguesa inovadora ou na escrita portuguesa inovadora.

No quadro 2, situo cronologicamente a escrita portuguesa conservadora no período de ca. 1175 a ca. 1275 por ser de 1274 a mais tardia manifestação clara que conheço da escrita portuguesa conservadora ${ }^{4}-$ veja-se, a seguir, o texto 3. Pode caracterizar-se assim o primeiro século do português escrito como o que precede a imposição da escrita "normalizada" da chancelaria régia, permitindo, por isso, o desenvolvimento de uma escrita portuguesa "marginal" (leia-se escrita como 'família de escritas').

A data de 1175 é apontada como limite inicial para o período de existência da escrita portuguesa conservadora por ser de 1175 a Notícia de Fiadores de Paio Soares Romeu e serem aproximadamente da mesma data a anotação de despesas de Pedro Parada e o Pacto entre Gomes Pais e Ramiro Pais, conforme se disse acima. Mas os antecedentes da escrita portuguesa conservadora situam-se bem mais atrás, como ilustram os fragmentos, longos e muito romanceados, dos dois textos latino-portugueses que se transcrevem parcialmente a seguir (vd. texto 1 e texto 2), datados respectivamente dos anos de 1101 e 1125 e provenientes do mosteiro de São Cristóvão de Rio

4. Naturalmente, traços da escrita conservadora podem manifestar-se ocasionalmente em documentos escritos depois de 1274 . É o caso, por exemplo, da representação gráfica de /o/ por <u> (quando não pode estar em causa uma realização [+ alta] da vogal), bem como da representação da consoante fricativa palatal surda por $<\mathrm{s}>$. 
Tinto. É interessante notar como o documento de 1101 atesta dois casos de variação gráfica escassamente representados nos textos escritos em português. Refiro-me à possibilidade de o grafema $<\mathrm{u}\rangle$, a par de $\langle$ g $>$, representar a consoante oclusiva velar sonora (uomez 'Gomes') e à variação gráfica entre $<\mathrm{u}>$ e $<\mathrm{b}>$ quanto à representação das consoantes bilabiais, não-nasais, oclusiva e fricativa (uobis, bouis, uouis) - cf. Lorenzo (2003: 168-169). A forma uounado 'Bougado, top.' ocorre na Notícia de haver do abade Pedro, da segunda metade do século xII, atestando ambos os traços gráficos, os quais, no entanto, não se manifestam na maior parte dos textos escritos em português. Este facto sugere que o processo de selecção entre variantes gráficas antigas (de índole alfabética) não é apanágio exclusivo da escrita portuguesa inovadora, verificando-se também, ainda que numa escala mais limitada, na constituição da escrita portuguesa conservadora 5 .

\section{TEXTO 1}

\section{IAN/TT, Mosteiro de São Cristóvão de Rio Tinto, mao 1, no 9 (Ano de 1101)}

In dei nomine ego uomez et pater suo pelaio kaauiz. in domino deo eterna salutem amen. [...] faceremus uir deuotus frater martinus de sõo cristoforis kartula de ereditate mea pro/ 5 pria de auiorum meorum et de parentorum meorum et de parte de mea matre $\mathrm{ii}^{\text {as }} \mathrm{v}^{\text {as }}$. est una quin $/{ }^{6} \mathrm{ta}$ que fuit de mendo kaauiz; et alia quinta de pelagio kaauiz; et damus ad marti/7nu frater duas quintas que fuit de meo patre et de mia matre de ipso regu que uen pora $/ 8$ uarcena et sparte per illo kasal. et quomodo sparte con mituceli. et comodo $/ 9$ sparte per illo termio de pena uncturella et conclausi illa per illa anta de super ${ }^{10}$ sangimir et per illo terminu de porritius malus et conclausi. illa per illo monte de laurero $/{ }^{11}$ et conclausi illa per illa aqua de ipso frexenario; damus a bouis ipsa hereditate proque ac $/{ }^{12}$ cepimus de uos xi soldus. et leisauimus a uouis alios tantos in dublo et istos solid $u s \mathrm{de}$ fia $/{ }^{13}$ turia que fiauit tuo saio (?) nomine uomez pelaiz; que preserunt saiones de condesindo cundisalbiz; $/{ }^{14}$ in parata; ita ut de odie in dia sedea ipsa hereditate de iur de uomez; pelaz; et de pelaio kaauiz; $/ 15$ abrasa et in iur de martin $u$ f frater tradicta adque confirmata [...] et ego uomeze pelaiz; et pela/ ${ }^{19}$ gio kauiz; a tiui frater mar[ti]nus facimus cartula firmitatis manus nostras rouorauimus $/ 20$ nodu $m$ die quo eri $\mathrm{x}^{\mathrm{o}} \mathrm{kalendas}$ maias In era Mcxxx ${ }^{\mathrm{a}-}$ viiii $^{\circ} / 21$ sabato. sancto. Qui presentes fuerunt uideru $n$ t et audierunt $/ 22$ Ioan testis icia testis ero testis eirigu testis aluitu testis pelagio presuitero nodui

5. Valeria a pena observar se algumas grafias isoladas ou raras que se encontram nos textos do primeiro século da produção escrita em português estarão mais generosamente representadas nos textos latino-portugueses. Por ex.: pezena 'pequena', quitazio 'quitação' (Martins 1999: 502); faczades 'façades', seruiczo 'serviço' (Martins 2001b: 343), forxa 'força', auéénxa 'avença' (Souto Cabo 2004b: 382); mixas 'missas' (Souto Cabo 2004a: 595). 
TEXTO 2

IAN/TT, Mosteiro de São Cristóvão de Rio Tinto, mao 2, nº 1 (Ano de 1125)

Jn dei nomine ego Muniu soariz et uxor sua Bona midiz. in domino deo eterna salutem amen. plaquid nobis per bona pacis et uolútas. et facimus ad uobis Guncaluo meendiz et ad uxor uestra Guntina $/^{2}$ gutierriz kartula kambiacionis uel contramudacion. et firmitatis de hereditate nostra propria que abemus in uilla quos uocitant sancti. iohani de madeira subtus. mons. parada ioaz discurrente rribulo ur propter ciuitas sancta $/ 3$ maria in loco predicto sancti iohani ille nostro kasale integro et de kasal de (..) de domina palla et de sisuerto vi ${ }^{\mathrm{a}}$ integra et de hereditate de Tosaru uermuiz et de uida uermuiz vi ${ }^{\mathrm{a}}$ integra. et de hereditate de quintana de xiiii quiniones $/ 4{ }^{\circ}$ integro et de hereditate de gudinu gimarti. de xxiiii ${ }^{\circ}$ quiniones. $\mathrm{i}^{\mathrm{o}} \mathrm{i}$ tegro de hereditate $\mathrm{d} e$ freosendi $\mathrm{d} e \mathrm{iiii}^{\mathrm{a}}$. $\mathrm{vi}^{\mathrm{a}}$. integra. et divident. ipsas hereditates per fundones et inde per mamulla de faroi et per illa strada et fer in ille moro/ 5 zo de illas pedras et uadi ad ille ualo qui sparte Toseiru. uermuiz cum quintana et fer in ille marco. de Astar. et inde per rribulo de Astar infesto et inde per illa strada maurisca et inde per ubi strema cum Ascarigu et inde $/{ }^{6}$ per illa ponte terrenia. et uadi perille fontano que intra in Astar et inde per ille rego de illa agua qui se leua de astar et fer in ille morouzu. de super ille mulinu. de kasal de ero et torna ad ille uallo. qui sparte kasal de Aluaro $/$ et de ouruida et inde sparte per mamula de gudemir. et inde per ille uallo qui sparte cum faria et fer in ur. et claude in fundones. et accipimus de uobis. pro ipsa hereditate illa que uobis ganastis de meendo eriz. in cessar et $/ 8$ illa rrotea. de tras ped[r]a mala quanta inde teniatis. in iure. sicut parte cum milieirodus. et cum Mazanaria. tantum nobis et uobis. bene complacuid. et uos destis et nos accipimus [...] facto kartulam contramudacionis. die eri. era MCLxiiia ${ }^{a}$ ego Muniu. ${ }^{12}$ soariz et uxor mea bona midiz ad. uobis Guncaluo meendiz et ad uxor uestra Guntina gutierriz in hanc kartulam. kambiacionis uel contramudacionis. et firmitatis magn $u s$ nostras rouo ${ }^{13}[\mathrm{raui}] \mathrm{m} u s$. hic inadimus de Kasal de Ascarigu viii ${ }^{\mathrm{a}}$. minus iiii a ata ille fontano que uen de illa proua et uadi per illa ponte terrenia. et de ista que iam condudimus. sacamus in$\mathrm{d} e$. hereditate $\mathrm{d} e .{ }^{14}$ uida midiz de quintana de scomdit que. sparte de kasal de Ascarigu. ata cum toseiru uermuiz. hic testis Petro testis. Diago testis $/{ }^{15}$ iohane testis. Suario testis. Pelagio scripsi notui

TEXTO 3

IAN/TT, Mosteiro de São Pedro de Pedroso, Maço 5, 24 (Ano de 1274)

In Era. $\mathrm{M}^{\mathrm{a}}$. $\mathrm{CCC}^{\mathrm{a}}$. $\mathrm{xij}^{\mathrm{a}}$. Sapiant omnes tam presentes quam futuri. Quod $/ 2$ ego Johanis suerij ${ }^{\mathrm{d} e}$ auintes facio mea manda. In primis mando $/ 3$ meo corpore sepeli- 
re in Monasterio Petroso $e$ mando ibi mecu $m$ lecto $/{ }^{4} \mathrm{cu} m$ una cozodra. $e$ cum una almuzela. $e$ una colcha. $e$ unu $m / 5$ chumazu Item unu $m$ modium terzadu de pam Item mando unu $m$ boue $m$ que $/ 6$ uocitant benfectu. Item vij. rezellos ouellas $e$ capras $e$ unum $\Gamma$ porco. Item iij llibras ad fratres por pitancia. Item mando ad Ecclesiam de $/^{8}$ Sancti Pet $r i$ de auintes por meas decimas. iijj. rexellos e unum porco. e. i. $/ 9$ quarteiro de pam Item. mando. x. soldos ad gaphos de porto. Item. x. soldos. ${ }^{10}$ ad opera de Sancta Maria. Item ad meos afillados. x. soldos. Item mando. i. ${ }^{11}$ libra de denarios por cera. Istis sunt testes qui uiderunt e audierunt Dominus vin/ ${ }^{12}$ centius Comicus de portu. e Martim petri miles. e Dominus Didacus Rector Ecclesie ${ }^{13}$ de Auintes. In super recipio. Matheus iohanis por meo filio per consensum de Martim $/ 14$ iuanes meo filio $e$ dent ad illu $m$ viij. morabitinos $e$ non plus. Item mãdo $/ 15$ Maria peceena mea neta. pequena mea neta. in simul cum Maria marti. una uaca cum $/ 16$ sua filia. que uocitant uermella. Item

$/{ }^{17}$ In super istas debitas que debet dare. Johanis suarez. x. morabitinos $/ 18$ ueteros. e mando dos. x. morabitinos ut faciant inde mandatum quomodo $/ 19$ Maria. marti quomodo ego mandaui ad illam facere. Item ad Monasterio Petrosi $/ 20$ vj. libras por hereditate que ego tenui de Monasterio Item Petrus feu. i. morabitino. Item $/^{21}$ mando quod si uenierit aliquis homo de bono testimonio quod ego debet dare $/^{22}$ ad illum. i $n$ treguent illu $m$ de illas causas que illos dixerint.

${ }^{23}$ In super istos denarios que debent ad Johanis suerij' dare. In primis Petrus de sua ${ }^{24}$ madre. iij. morabitinos ueteros. Item Pelagius petri. ij. morabitinos e viiij. soldos. Item $\mathrm{Giral} /{ }^{25} \mathrm{du}$ de auintes. morabitinos. duos. $e$ iij. soldos que debet dare. Item. Petrus alua/ ${ }^{26}$ riu. i. morabitino. Item Petrus marra ij. morabitinos e xviij. soldos. Item Martim de sousa $/ 27$.ij. morabitinos e xv. soldos. Item Dominicus cabanues. i. morabitino. Item Johanis marti. xxx. $/{ }^{28}$ viij. soldos. Item Giraldu de gudia. iij. libras. Item Annar pegadu .i. ${ }^{29}$ libra. Item Dominicus suariz de sangimir. i. morabitino. Item Judex de gundemar $\beta 0$.i. morabitino. Item Martim de matu. i. morabitino. Item Dominicus mendiz de campos. ij. morabitinos. ${ }^{\beta 1}$ Item debet dare mibi de Monasterio. vj. libras que fuerunt de neemo $/ 32$ In ssuper ego cognoui quod ista est hereditate. quod Johanis suerij'. tenet de ${ }^{\beta 3}$ Monasterio. in quintaas scilicet. unu $m$ casale. Item una uarzena que uocita $n$ t $/ 34$ arodondela.

${ }^{35} \mathrm{Era} . \mathrm{M}^{\mathrm{a}}$. CC. Lija ${ }^{\mathrm{a}}$. Ista est hereditate que habet Monasterio de Petroso in Cauto de Auin $/{ }^{36}$ tes . Scilicet. In Quintana (?) duos Casalia. $e$ v. fossadeyras. Isti $/ 37$ sunt homines qui solebat morare. in illas Petrus gagu. debet dare $\beta^{38} e$ Suerius pet $r i$ iiij. soldos. e media. quaira de triigo. in Mensse Maij'. Item Menendus ${ }^{39}$ uenegas e Petrus mauro. debet dare. iiij. soldos. e media quaira de triigo d $/{ }^{40}$ Item Dominicus Campos debent (sic) dare. Dominicus ribeyru e Gundisalus petri debent ${ }^{41} \mathrm{da}-$ re. iiij. soldos. e media. quaira de triigo.

${ }^{42}$ Isti sunt testes. Abbas de Sancti Tirsi Dominus Menendus. $e$ Prior $/ 43$ de Gumaraes. MaGister scola. e Prior de manzelliss. Johanis notuit ${ }^{44}$ Item Rex Dominus Alphonsus confirmauit isto testamento. 
${ }^{45}$ In super habet Monasterium in villa de Canpos. una Leyra nus murmu $/{ }^{46} \mathrm{es}$. Item termini Inter marcu $e$ marcu. est de Monasterio. quarta $e$ vij ${ }^{\mathrm{a}} . /{ }^{47} \mathrm{~d} e$ toto barreyrus. $e$ illud soutu $m$ que fuit de Didacus $/{ }^{48}$ róóriquiz de fontes.

No verso:

${ }^{49}$ Isti sunt Judices quod fuerunt Johanis suerij' de auintes. $e$ Dominicus $/{ }^{50}$ Didacus de auintes. e Sunt Testes Petrus de deus $e$ Pelagius petri de auin $/{ }^{51}$ tes. Laurencius $\mathrm{d} e$ iaca. e Johanis nuniz. $e$ fernand $u s$ de bazia. $e$ Petrus $/{ }^{52}$ petri. de vilar. $e$ Martim gagu. e Johanis uaqueiru. e Giraldus maiodom $u s$ (?) $/ 53$ de cautu. $e$ istud fuit super demanda que faciebant Dominicus petri de baza de una $/ 54$ hereditate de Sancta crux. Istj sunt testes que eceperunt super ista $m$ hereditate. Martim /55 caballu. $e$ Petrus chora. $e$ Pelagius uineiru. $e$ Simom de vilar $e{ }^{56}$ Johanis de maariz. e Petrus de deus. e Dominicus iohanis rector Ecclesie de vilar.

\section{OS TEXTOS NÃO LITERÁRIOS COMO FONTE DE CONHECIMENTO LINGUÍSTICO EM FUNÇÃO DO TIPO DE ESCRITA}

Algumas das característica da escrita portuguesa conservadora que apontámos na secção precedente tornam os respectivos textos inadequados para deles se extrair informação no que diz respeito a certas mudanças fonológicas. Tendo como referência a escrita portuguesa conservadora, Rita Marquilhas (2004) afirma:

Grafematicamente, ficam comprometidas algumas datações recuadas para processos como o da elevação das vogais átonas baseadas nas grafias medievais $u, i$, uma vez que parece questionável a sua correspondência imediata a articulações com o valor [+ alto] (v., para a grafia $u$ em posição final, Martins 1985); também se deverá manter cautelosa a datação do processo de ensurdecimento das sibilantes galegas (ex.: Mariño Paz 1998: 115-117) (Marquilhas 2004: 487).

A afirmação parecer-me-ia inquestionável se não supusesse a não separação entre as duas escritas portuguesas acima identificadas, e correspondentemente entre dois tipos de textos escritos em português até ao terceiro quartel do século XIII. Cingindo-me à fonologia histórica do português, continua a parecer-me hoje (como em Martins 1985) que o manuscrito de Toledo do Testamento de D. Afonso II, de 1214, aponta para a existência de realizações altas das vogais átonas finais já na primeira fase do português antigo. O documento em causa é fiável enquanto testemunho da evolução do vocalismo átono em português porque a sua escrita é a escrita portuguesa inovadora à qual não pertence a opção de representar as vogais /o/ e /e/, quer acentuadas quer não acentuadas, por $<\mathrm{u}>\mathrm{e}<\mathrm{i}>$ respectivamente. Assim no 
Testamento de D. Afonso II, de 1214, em particular no manuscrito de Toledo, as vogais /o/-/e/ nunca se encontram representadas por $\langle\mathrm{u}\rangle /<\mathrm{i}>$ quando em posição acentuada ou em posição átona não final. A restricção das grafias $\langle\mathrm{u}>/<\mathrm{i}\rangle$, na situação relevante, à posição átona final permite atribuirlhes o valor de "prova" (a avaliar em conjunto com evidência de outra natureza) que naturalmente não teriam se não se verificasse tal limitação. Ou seja, o Testamento de D. Afonso II, de 1214, não pode enquanto documento para a história do vocalismo átono português ser posto no mesmo plano que um documento em escrita portuguesa conservadora, como por exemplo a Manda de Margarida Garcia que a seguir se transcreve. Mais geralmente, a distinção entre escrita portuguesa inovadora e escrita portuguesa conservadora terá de ser considerada ao tomar-se os textos escritos em português nos séculos XII-XIII como fonte de conhecimento linguístico.

\section{TEXTO 4}

IAN/TT, Mosteiro de Santa Maria de Tarouquela, Maço 8, s/n (primeira metade do século xiii)

hec ee nuntia di manda qi fiz margarida. garcia cum seu maridu. seu curpu e sa irdadi e cunuim a sabir cal. mand $<\mathrm{a}>\mathrm{u}$ a taroucela. u casal da nu $/{ }^{2}$ geira. i litu di liteira cumpridu. Santa iucaia. i. uaca. i. arca. i. modiu di pam. pur quitacum di seu dizimu. iiii. riselus. $\mathrm{u}<\mathrm{c}>$ asal da cituleira. $/ \beta$ a santa cãuba. pur si e pur sa madre u casal di lourincu istiuaiz mandau a garcia istiuaiz. cun a uina du uale qi istu li da pur dum. $/{ }^{4}$ e pur isti dum qi li da. dali garcia istiuaiz u casal du souto de múreira. e da uina du iau. ama distiuam. i. bicira. i. almucela. i. iuma $/{ }^{5} \mathrm{cu}$. Martim iuanis. i armeiu. a see. i. medi<u> marauidi. a sa martiu di muimenta. i. mediu a sa martiu di furnelus. $/ 6$ ous gafus. i. riselu. pir sa irdade e pir seu auir e pir. vi. liuaras qi li da garcia istiuaiz qui li canti. i. anal di $/ 7$ misas. ista manda leisu a pidru piriz. e pidru iuanis. e garcia istiuaiz ${ }^{8}$ qi mi faca $m$ tudu meu diritu ni $m$ filu ni $m$ fila no $m$ siia pudirusu $/ 9$ du meu filar nim pouco nim mutu. mius distu sijr pag $<\mathrm{a}>/{ }^{10} \mathrm{du}$. filu $\mathrm{O}<\mathrm{u}>$ fila qi ista manda qera brita (sic) siia maldi/ ${ }^{11}$ tu $\mathrm{e}$ cunfusu.

Não pretendo retomar aqui extensivamente a questão da elevação do vocalismo átono (cf. Martins 1985). Limitar-me-ei a esclarecer porque tomo a grafia $u$ que se encontra no manuscrito de Toledo do Testamento de D. Afonso II, de 1214, nas palavras susu e $u$ (artigo definido e pronome pessoal) como indicadora da articulação da vogal final arredondada como [u] no português do início do século xiII. O objectivo deste excurso será ilustrar 
porque considero indispensável manter clara a distinção entre as duas escritas portuguesas observáveis nos textos produzidos entre ca. 1175 e ca. 1275 .

Thomas Hart (1955, 1959) e Herculano de Carvalho (1962) defenderam que os fonemas /e/, /o/ tinham, em posição final, as realizações [i] e [u] no português quinhentista. Os argumentos aduzidos por Thomas Hart e Herculano de Carvalho a favor de uma cronologia desencontrada para a elevação das vogais átonas finais, por um lado, e das pretónicas, por outro, com as primeiras a manifestarem realizações [+ altas] mais cedo do que as segundas apoiam-se fundamentalmente em dados da geografia linguística. As realizações [i]/[u] para as vogais átonas finais dominam a maior parte do território brasileiro (que desconhece a elevação generalizada das pretónicas), ocorrem nos crioulos de base portuguesa, e são no português europeu um traço dialectal que se afirma nas mais diversas regiões. Uma tal extensão geográfica de -[i] e -[u] fala a favor da sua antiguidade. O facto de territórios geograficamente descontínuos (Brasil, Cabo Verde, territórios asiáticos), mas colonizados todos eles por falantes do português europeu no século XVI, apresentarem idênticas realizações para as vogais átonas finais, realizações que são ainda as de grande parte do português europeu, faz supor que [i]/[u] era, no século XVI ou mesmo antes, a pronúncia mais generalizada das vogais átonas finais do português ${ }^{6}$. Por outro lado, em dialectos do Algarve e em variedades do crioulo de Cabo Verde, [i]/[u], hoje apocopados, deixaram nas vogais tónicas, através da metafonia, vestígios da sua anterior existência. Tal situação aponta, mais uma vez, para uma grande antiguidade dessas realizações ${ }^{7}$.

A favor da maior antiguidade do processo de elevação das vogais átonas finais relativamente às pretónicas fala ainda, conforme observou Rita Marquilhas (2004), o facto de o português contemporâneo exibir "excepções" à regra de elevação para as vogais pretónicas, enquanto a elevação das finais escapa a qualquer "excepção", operando irrestritamente.

No que diz respeito à vogal átona final [+ arr], é necessário considerar adicionalmente que a sua história se encontra associada à da metafonia nominal, o que nos faz remontar ao português pré-literário. A metafonia nominal (portuguesa e leonesa) indica que em certas regiões da Península Ibérica $o$ longo e $u$ breve latinos evoluíram diferentemente em posição final, tendo o último conservado o timbre [u]. Por isso, a vogal tónica radical elevou-se

6. Hart $(1955,1959)$ refere-se aos dialectos do português europeu e ao português do Brasil; Herculano de Carvalho (1962c), aos dialectos do português europeu, ao português do Brasil e aos crioulos de Cabo Verde. Mas ambos recorrem a um mesmo tipo de argumento, o da coincidência linguística entre áreas geograficamente descontínuas. Este argumento fica reforçado se também forem considerados os crioulos de base portuguesa da Ásia.

7. Cf. Carvalho (1962a); Carvalho (1962b); Hammarström (1953); Lüdtke (1957: 101-106). 
nas formas do masculino singular onde ocorria uma vogal [+ alta] em posição final (com origem em $u$ breve latino), mas conservou o seu timbre nas formas do masculino plural onde não existiam condições para a elevação já que a vogal final (com origem em o longo latino) era [- alta].

Menéndez Pidal (1926), em Orígenes del español, mostrou que a distinção entre [u] (com origem em $u$ breve latino) e [o] (com origem em o longo latino) se conserva em dialectos leoneses da região das Astúrias, onde não foram alteradas as condições que determinaram a produção da metafonia nas formas nominais do masculino singular, mas já não no plural ${ }^{8}$.

Deve então perguntar-se se o [u] final do português contemporâneo, nas formas nominais do masculino singular, será o resultado directo de $u$ breve final latino, conforme sugeriram Dámaso Alonso $(1958,1962)$ e Herculano de Carvalho (1962c) ${ }^{9}$. A realização -[u] ter-se-ia depois alargado aos plurais nominais, às formas verbais de primeira pessoa do presente do indicativo e às palavras gramaticais originadas em formas latinas com o longo final, como acontece em alguns dialectos leoneses ${ }^{10}$.

É no contexto sumariamente traçado acima que os dados do manuscrito de Toledo do Testamento de D. Afonso II, de 1214, adquirem relevância, ao apontarem para a existência de realizações altas das vogais /o/ e /e/ limitadas à posição átona final.

Ignorados os casos em que $u$ final indicia presumivelmente processos de semivocalização ( $m e u$, seu, Deus, eu) ou de assimilação do traço [+ alto] da vogal acentuada (nenguu, alguus), o Testamento mostra a grafia $u$, a representar um segmento vocálico em posição final, em palavras derivadas de étimos latinos com $u$ breve final (9 ocorrências de susu e 10 ocorrências de $u$, artigo definido e pronome pessoal). A grafia $u$ ocorre uma única vez numa forma derivada de base latina com o longo na sílaba final. Trata-se da forma

8. Dessa distinção mantêm-se vestígios em documentos do Norte da Península Ibérica nos séculos X e XI (Menéndez Pidal, 1926: \$35.3).

9. Note-se que a referida oposição, além de se manter em dialectos das Astúrias e Sardenha, conforme aponta Menéndez Pidal (1926: \353), vive ainda em dialectos do centro e sul de Itália (cf. Alonso, 1962: 133). Nestas áreas dialectais, [o] (final), por oposição a [u] (final), é a terminação das formas verbais e adverbiais em cuja base está um [o] final latino; ou seja, a oposição -[u] / -[o] não se restringe à flexão nominal: "Encore à l'heure actuelle -o et - $u$ sont restés distincts en Lougodorien: bona, bonos, tempus, kanto, kando; pour l'Italie centrale, cf. diko à côté de tempu à Aquila, Rieti, Norcia, Pitigliano, etc. De même en Asturien 1e pers. sing. o, noms plur. os, komo, kresiendo, kuando, sedo, solo, mais sing. $u$, adj masc. $u$, neutr. o" (Meyer-Lübke, 1890: \$308).

10. "el asturiano central mantiene, neta, la distinción $-u$ y -os, o, en general, -o. En otras zonas de dialecto leonés hay condicíones menos claras; de algunas (Maragatería y tierra de Astorga, Babia y Laciana) hay datos se diría seguros de que lo mismo se pronuncia sing. $-u$ que plural $-u s$ : es decir que se ha llegado a una situación como la del portugués" (Alonso, 1962: 123). 
de plural masculino do artigo definido, us. Em formas verbais ou conjuntivas com $o$ longo final etimológico, a grafia $u$ não ocorre nenhuma vez.

Se o Testamento de D. Afonso II, de 1214, e em particular o manuscrito de Toledo, manifestasse propensão latinizante ou apresentasse o tipo de "traços criativos" próprios da escrita portuguesa conservadora que identificámos na secção precedente, a grafia $u$ das formas susu e $u$, us seria linguisticamente irrelevante. Como nenhuma dessas situações se verifica, a mesma grafia pode ter-se por reveladora de um traço fonológico do português da primeira metade do século XIII.

$\mathrm{O}$ argumento de que a grafia $u$ que esporadicamente se encontra nos textos portugueses do século xIII, em posiçao final, traduziria uma opção "latinizante" por parte de alguns escribas, parece particularmente desajustada no caso do manuscrito de Toledo do Testamento de Afonso II, de 1214. Quando comparado com documentos coevos produzidos fora da chancelaria régia, o Testamento, em ambas as versões que chegaram até nós, apresenta uma escrita surpreendentemente estabilizada e liberta de marcas da tradição scriptográfica tardo-latina (cf. Martins 1999) ${ }^{11}$. No caso da forma $u$, em especial, cabe notar que a opção latinizante para representar quer o artigo definido quer o pronome pessoal de terceira pessoa está bem representada nos documentos particulares escritos em português a partir de 1175, traduzindo-se na forma gráfica illo/illu. Não coincide pois com a forma $u$ que o manuscrito de Toledo do Testamento apresenta.

O distanciamento do Testamento relativamente aos "traços criativos" da escrita portuguesa conservadora, por outro lado, é bem visível na observação sistemática da distinção gráfica entre consoante oclusiva (ou fricativa labial) surda e sonora, sendo a variação gráfica neste domínio um dos traços mais comuns dos textos que representam a escrita conservadora. Particularmente relevante é o facto de o copista do manuscrito de Toledo optar sistematicamente por representações gráficas diferenciadas para as consoantes africadas dentais surda e sonora, no que contrasta com o copista do manuscrito de Lisboa e se revela um percursor em matéria de "normalização" gráfica. Especificamente no que respeita à representação das vogais átonas finais,

11. O copista do manuscrito de Toledo em particular mostra uma precoce vontade de evitar a variação gráfica na representação de um mesmo som; tome-se como exemplo a representação sistemática da consoante fricativa (ou africada) palatal sonora por $i$ (Cf. Martins 1985 e Castro 1991). O facto de ser precisamente este copista que manifesta variação na representação gráfica da vogal final /o/, nos casos em que admiti que a sua realização seria já [u], parece-me só ser interpretável como resultado da tensão entre a tendência para respeitar uma tradição gráfica bem estabelecida (e fonologicamente motivada) e a tendência para a adopção de grafias mais coladas ao plano fonético. 
é de notar que se o copista do manuscrito de Toledo usasse de duas opções gráficas, $<\mathrm{O}>\mathrm{e}<\mathrm{u}>$, para representar uma vogal média, arredondada, em posição final, se esperaria que a grafia $u$ também se manifestasse, por exemplo, nas formas verbais de primeira pessoa do presente do indicativo, que são frequentes no Testamento.

Dada a natureza inovadora da escrita do Testamento de D. Afonso II, de 1214, que se revela de forma particularmente acentuada no manuscrito de Toledo, o quadro linguístico delineado por este documento no que diz respeito à vogal final /o/, é na minha opinião o seguinte: realização do descendente português de $u$ breve final latino como [u] - grafado $<\mathrm{O}>$ ou $<\mathrm{u}>$; realização do descendente português de o longo latino seguido de [s] final (plurais nominais e pronominais e plural dos artigos definidos) como [u] - grafado $<\mathrm{O}>$ ou $<\mathrm{U}>$; realização do descendente português de $o$ longo final latino (formas verbais, adverbiais e conjuntivas) como $[\mathrm{o}]-$ grafado $<\mathrm{O}>$.

Admitindo com Dámaso Alonso $(1958,1962)$ que no português moderno [u] final das formas nominais do singular resulta directa e ininterruptamente de $u$ breve final latino, e de acordo com os dados fornecidos pelo manuscrito de Toledo do Testamento de D. Afonso II, essa realização [u] ter-se-ia estendido, num primeiro momento, aos plurais nominais, só mais tarde atingindo também as formas verbais, adverbiais e conjuntivas. Ou seja, a uma etapa de generalização morfologicamente condicionada, ter-se-ia seguido uma generalização não condicionada da regra de elevação de /o/ átono final para [u]. Este processo evolutivo, a ser confirmado, constituiria uma possível explicação, ainda que parcial, para o facto de as línguas ibéricas que apresentam realizações altas para as vogais átonas finais, o português e o leonês, serem também línguas com metafonia nominal. Na origem quer da metafonia quer da elevação do vocalismo átono final, pelo menos na série velar, estaria a realização de $u$ breve final latino como [u] em áreas do ocidente ibérico. Esse -[u] final (que no português condicionou a elevação de um grau das vogais tónicas baixas é, ó), em época posterior, e em consequência de sucessivos processos de generalização, ter-se-ia tornado a realização geral do fonema /o/ em posição final, independentemente da classe de palavras em que o mesmo ocorresse. Esta elevação da vogal velar em posição final teria, por outro lado, favorecido a elevação da sua correspondente palatal em idêntica posição ${ }^{12}$.

12. No Testamento de Afonso II, a conjunção condicional apresenta quer a grafia $-i,(s) s i$, com 11 ocorrências no ms. da Torre do Tombo, quer a grafia $-e,(s) s e$, com 1 ocorrência no ms. da Torre do Tombo e 12 no ms. de Toledo. Parece assim, numa primeira aproximação, que a evolução $-i$ (de $i$ longo latino) > $-e$, que Huber $(1933$ : $\$ \$ 15.3$, 152) e Williams (1938: $\$ 47.1$ ) situam no século XIV, se teria iniciado em época muito anterior. Esta evolução corresponderia a uma ex- 


\section{A PRODUÇÃO LITERÁRIA INICIAL}

O ciclo arturiano da post-vulgata, composto em França, por um autor anónimo, entre 1230 e 1240, teve larguíssima difusão na Península Ibérica, estando hoje representado quer por manuscritos portugueses quer por manuscritos castelhanos. No início do século xx, Carolina Michaẻ is de Vasconcelos sugeriu, sem chegar a apresentar os factos que suportariam a sua opinião, que a primeira tradução peninsular da Demanda do Santo Graal seria portuguesa - "Do confronto com o texto castelhano resulta que esse é tradução do português, retocado para a impressão com pouca perícia" - e associou a D. Afonso III e seu círculo a introdução e difusão em Portugal da versão post-vulgata da matéria da Bretanha (cfr. Vasconcelos 1904: 512; 1908: 6). Na mesma época José Joaquim Nunes (1908), ocupando-se do Livro de José de Arimateia, exprimiu opinião idêntica à de Carolina Michak̉ is de Vasconcelos e acrescentou argumentos linguísticos a favor da localização da tradução portuguesa do ciclo (feita directamente a partir da fonte francesa) "nos fins do seculo XIII ou nos principios do seculo XIV" (p. 226). É, contudo, com o artigo de Rodrigues Lapa, de 1930, dedicado à Demanda do Santo Graal, que a tese da prioridade do texto português sobre o texto castelhano, e da filiação deste naquele, ganha consistência, passando a fundar-se em argumentos linguísticos e filológicos sólidos (cfr. Lapa 1930, 1982). Em 1951, Luís Filipe Lindley Cintra adere a esta tese, considerando que Rodrigues Lapa "claramente demonstrou a prioridade do texto português" (pp. L-LI). Mais recentemente, e deslocando o foco de observação da Demanda para o José de Arimateia, Ivo Castro esclareceu o contexto histórico em que se produziu a importação para Portugal, por Afonso III, dos romances arturianos do ciclo da post-vulgata e identificou o tradutor do ciclo (constituído pelo Livro de José de Arimateia, o Merlim e a Demanda do Santo Graal). O tradutor, cujo nome é mencionado quer no José de Arimateia português quer na Demanda castelhana, foi um frade da Ordem de Santiago, João Vivas, documentado na região de Lisboa em 1240 e 1263. Cfr. Castro (1983, 1984, 1988, 1993).

Um século de investigação filológica mostrou portanto que durante o primeiro século do português escrito houve não só produção poética mas tam-

tensão analógica da realização - $e$ aos casos de - $i$ etimológico, raros no português. Mas deveremos perguntar-nos se a progressiva substituição, em posição final, da grafia $i$ por $e$ (nas palavras com $i$ etimológico), substituição já registada no Testamento, reflectirá na verdade a mudança "analógica" - $i>-e$. Em alternativa, poder-se-á interpretar a substituição gráfica de $i$ por $e$, que se acentua a partir do século xIV, como um processo de regularização ortográfica numa altura em que, dada a elevação $-e>-i,<\mathrm{e}>$ está a caminho de tornar-se a representação gráfica usual de -[i]. Cria-se assim um paralelismo na representação das duas vogais finais altas, [i] e [u], por $<\mathrm{e}>\mathrm{e}<\mathrm{O}>$ respectivamente, grafias, aliás, fonologicamente motivadas. 
bém produção de prosa literária, em português, pelo que parece redutor continuar a limitar a discussão em torno dos "textos portugueses mais antigos” à produção não-literária. Tal restrição encontra-se, no entanto, solidamente estabelecida por assentar na premissa inquestionável de que uma cópia não é linguisticamente equiparável a um original (assim como não o é noutros aspectos, irrelevantes no presente contexto). Sugerirei, a partir de um caso ilustrativo, que é possível saber-se até que ponto uma cópia tardia é fiel ao texto original (desaparecido), relativamente a factos linguísticos observados singularmente. Uma vez avaliada casuisticamente a proximidade entre o original perdido e a cópia, poderá esta ser resgatada na sua qualidade de testemunho linguístico do tempo de produção do original.

Ao analisarem numa perpectiva estratigráfica a Demanda do Santo Graal, traduzida para português no tempo do rei Afonso III mas conhecida através de um testemunho único do século xv (o manuscrito de Viena), Rodrigues Lapa (1930, 1982) e mais recentemente Heitor Megale (2001) notam que o texto apresenta um conjunto de formas que não parecem atribuíveis ao copista quatrocentista, sendo antes manifestação da camada antiga, duocentista.

O primeiro nível de percepção de estratos lingüísticos sobrepostos é, sem dúvida, o do léxico. (...) podem documentar a camada mais antiga, a simples ocorrência de palavras como: adur ..., aenfesto ..., afolar ..., aginha ..., al ..., amedes ..., antecoante ..., aque (...) chus ..., cordo ..., cras ..., daenuidos ..., dende ..., dõado ..., domaa (...) eixamete ..., eixeco ..., eixerdar ..., endoado ..., enfinta ..., enmentar ..., enquisa ..., entendedor ..., envidos ..., enxeco ..., er (...) verça ..., vervejar ...; vezibõo ..., xe ... (Megale 2001: 134-135).

Identificando formas antigas (lexicais e gramaticais), Lapa $(1930,1982)$ e Megale (2001), mostram que quem copiou, no século xv, o texto da Demanda não fez desaparecer o estrato linguístico primitivo mas não nos esclarecem sobre a extensão das áreas de visibilidade dessa camada antiga.

Um trabalho em curso, que constituirá a dissertação de mestrado a apresentar por Laura Maria Martins Filipe à Faculdade de Letras da Universidade de Lisboa, permite-nos acrescentar às observações de Lapa (1930, 1982) e Megale (2001) evidência quantitativa ${ }^{13}$. A dissertação é dedicada ao estudo

13. O Corpus textual do qual foram extraídos os dados é o que se encontra disponibilizado pelo TMILG (Tesouro Medieval Informatizado da Língua Galega, projecto do Instituto da Língua Galega / Universidade de Santiago de Compostela, dirigido por Xavier Varela) e pelo CIPM (projecto do Centro de Linguística da Universidade Nova de Lisboa, dirigido por Maria Francisca Xavier), acrescido da Demanda do Santo Graal (ed. Piel-Nunes), do Livro de José de Arimateia (ed. Ivo Castro), da Crónica de D. João I (ed. Freire-Entwistle), da Crónica de D. Pedro (ed. Macchi), da Crónica de D. Fernando (ed. Macchi), e da obra de Gil Vicente (ed. Osório Mateus). 
do advérbio ar/er do português e galego medievais. A distribuição desse advérbio nos textos do século xiII ao século xv, que o trabalho de Laura Filipe estabelece, mostra com surpreendente limpidez que o manuscrito quatrocentista da Demanda é, quanto ao aspecto em análise, um retrato fiel do original duocentista. No testemunho quatrocentista da Demanda ocorrem com frequência significativa tanto ar como er, como é próprio dos textos portugueses do século XIII (e já não dos galegos, onde er ocorre raramente). Mas o facto essencial é que o número de ocorrências atinge um patamar que é exclusivo dos textos do século xiII, pois as manifestações textuais de ar/er reduzem-se drasticamente logo no século seguinte. Concretizando, há 63 ocorrências de ar e 82 ocorrências de er na Demanda. Estes valores são equiparáveis aos do conjunto da produção poética de autores portugueses no século XIII (154 atestações de ar/er) ou das Cantigas de Santa Maria (174 atestações de $a r /$ er), mas situam-se a grande distância do texto em prosa do século XIV que apresenta maior número de ocorrências de er (a Crónica Geral de Espanha de 1344, onde ar não ocorre e as atestações de er não chegam a duas dezenas). Juntando, para o século xIv, textos não-literários e literários, portugueses, contam-se menos de uma dezena de exemplos de ar (todos na poesia) e quatro dezenas de er, número inferior ao que a Demanda, só por si, oferece. Nos textos do século xv, quando foi produzido o manuscrito de Viena que hoje é testemunho único da Demanda, já não existe ar e os exemplos de er decrescem para cerca de duas dezenas de atestações (16 em Fernão Lopes, 6 em Zurara). A comparação entre a Demanda e outros textos medievais (dos séculos XIII a XV) permite assim descobrir que os copistas quatrocentistas não apagaram nem atenuaram a presença na Demanda das formas ar / er, apesar de ar ser estranho aos textos do século XV e de er ter neles uma presença discreta. Particularmente significativo é o facto de o advérbio ar/er te sido, presumivelmente, conservado de forma generalizada, conforme se deduz do número de ocorrências que apresenta na Demanda. Talvez os copistas quatrocentistas tenham substituído alguns ar por er, visto que ar é mais frequente que er nos textos do século xiII, diferentemente do que se observa na Demanda.

Também no que diz respeito à produção poética, o rastreio do advérbio antigo ar/er produz resultados interessantes. Por um lado confirma a tese de Rübecamp (1933) de que a linguagem das Cantigas de Santa Maria apresenta traços tipicamente galegos; por outro lado mostra, contrariamente ao que pensava Rübecamp, que é possível observar aspectos da separação linguística entre galego e português nos Cancioneiros profanos, apesar de terem ocorrido processos de compilação e cópia que fariam supor uma normalização ocultadora de contrastes linguísticos. 
[Os Cancioneiros profanos], segundo as investigações realizadas até hoje, ainda que estas não tenham abrangido por ora todas as suas particularidades, oferecem um quadro lingüístico, até certo ponto uniforme, apesar de pertencerem a diferentes épocas e provirem de trovadores de diferentes países (portugueses, galegos, castelhanos e leoneses) (Rübecamp 1933: 7).

Já várias vezes se afirmou que a linguagem das Cantigas, ao contrário da linguagem dos Cancioneiros, ocupa uma situação lingüística muito especial: Carolina Michatis de Vasconcelos e Nobiling notam que as Cantigas [de Santa Maria], devido ao seu carácter religioso, se distinguem dos Cancioneiros profanos no seu vocabulário e estilo, enquanto que a respeito da sua fonética e morfologia se tem afirmado que os fenómenos caracterìsticamente galegos são mais frequentes nas Cantigas (Rübecamp 1933: 8).

Examinando, numa vista rápida, os resultados mais importantes do nosso trabalho não contidos no capítulo reproduzido acima, vemos que a concordância lingüística entre as Cantigas e os Cancioneiros observada com respeito ao hiato românico, é aproximadamente a mesma que se verifica em todos os outros fenómenos. Há, contudo, certas ligeiras diferenças que nos permitem ver nas Cantigas a direcção galega da evolução lingüística, em oposição aos Cancioneiros, cujo quadro geral tem um carácter mais português (Rübecamp 1933: 70).

Nas Cantigas de Santa Maria e na produção poética de autores galegos a forma er é rara, aparecendo quase exclusivamente ar (3 er para 171 ar nas Cantigas de Santa Maria e 5 er para 87 ar nos textos de poetas galegos dos sécs. XIII e XIV). Na produção poética de autores portugueses, em contraste com as Cantigas de Santa Maria e as composições de autores galegos, er tem bastante visibilidade ( 48 atestações de er para 122 de ar, nos sécs. XIII e XIV). Assim o advérbio ar/er aponta, em consonância com outra evidência linguística, para a separação entre as línguas escritas galega e portuguesa (mesmo no âmbito da poesia dita galego-portuguesa) e suporta a filiação galega das Cantigas de Santa Maria. Também neste caso fica a indicação de que o processo complexo de transmissão dos textos não bastou para encobrir certas propriedades originais, que podem ser identificadas.

O caso ilustrativo aqui considerado, permitiu-nos ver que nem toda a cópia desmerece o original. Dito isto, é óbvio que não ficamos autorizados a extrapolar qualquer generalização quanto à benignidade dos testemunhos não-originais. A sua natureza enquanto documentos linguísticos só pode ser avaliada circunstancialmente, observados caso a caso factos linguísticos que estabeleçam com clareza fronteiras linguistico-cronológicas. À medida que a investigação nesta direcção for acumulando resultados, alguns textos literários poderão tornar-se elementos da reflexão sobre a emergência do português como língua escrita na Idade Média. 
APÊNDICE: DOCUMENTOS PORTUGUESES ATÉ 1255

[Este apêndice não inclui os documentos portugueses que apresentam (alguns) traços scriptográficos leoneses (cf. Martins 1999:503-504; Souto Cabo 2004b:364); a datação provável apresentada é a estabelecida pelos editores referenciados para cada um dos textos, excepto no caso do Pacto de Gomes Pais e Ramiro Pais (vd. nota 1 supra)]

\section{A. Documentos datados}

1. Notícia de Fiadores de Paio Soares Romeu (1175. Martins 1999)

2. Nómina de manda e de dívidas de Pedro Viegas (1184. Souto Cabo 2003a)

3. Borrão do testamento de Pedro Fafiz (1210. Martins 1999)

4. Testamento de D. Afonso II (1214. Costa 1977)

5. Notícia de dívidas de Pedro Fafiz (1234. Martins 1999)

6. Nota de pagamento de dívidas de Pedro Fafiz (1234. Martins 1999)

7. Testamento de Dona Aldora Afonso (1243. Martins 1999)

8. Testamentos de Sancha Martins e Pedro Martins (1252. Martins 1999)

9. Dívidas de Pedro Martins e Sancha Martins (1252. Martins 1999)

10. Carta de foro de Telões de Aguiar (1255. Chancelaria de Afonso III. Duarte 1986, Banza 1992)

11. Carta de Foro de Condudo (1255. Chancelaria de Afonso III. Duarte 1986, Banza 1992)

\section{B. Documentos sem data}

12. Despesas de Pedro Parada (anterior à Notícia de Fiadores de 1175. Martins 1999)

13. Pacto de Gomes Pais e Ramiro Pais (ca. 1175. Souto Cabo 2003a)

14. Notícia de herdades de Paio Soares Romeu (ca. 1171-1177. Martins 1999)

15. Notícia de haver do abade Pedro (séc. XII, $2^{\text {a }}$ metade. Martins 1999)

16. Notícia de fiadores de Urraca Tolquidiz (séc. XII, $2^{\mathrm{a}}$ metade. Martins 1999)

17. Escrito de Paio Soares (séc. XII, $2^{a}$ metade. Souto Cabo 2003a)

18. Carta de Susana Fernandes concedendo aos moradores da Benfeita uma redução do foro que lhe deviam pagar (séc. XII, $2^{\text {a }}$ metade. Souto Cabo 2003a)

19. Manda de Pedro Alvites (séc. XII, $2^{a}$ metade. Souto Cabo 2003a)

20. Notícia de arras de Urraca Peres (séc. XII/XIII. Martins 1999)

21. Inventário de Toda Soares do Casal (ca. 1210. Souto Cabo 2003b) 
22. Notícia de Torto (ca. 1214. Cintra 1990, Costa 1977, Pedro 1994, Emiliano e Pedro 2004)

23. Finto dos casais de Lijó (ca. 1224-1225. Martins 1999)

24. Manda de Fruilhe Rodrigues de Pereira (ca. 1230. Souto Cabo 2003b)

25. Partição de Mor Martins e Durão Martins (ca.1235-1244. Souto Cabo 2003b)

26. Notícia de manda de Margarida Garcia (séc. XIII, $1^{\mathrm{a}}$ metade. Martins 1999)

27. Finto de partição de Rodrigo Nunes (séc. XIII, $1^{\text {a }}$ metade. Martins 1999)

28. Manda de Mendo Ermigues (séc. XIII, $1^{a}$ metade. Souto Cabo 2003b)

29. Inventário de Martinho Pais (séc. XIII, $1^{a}$ metade. Souto Cabo 2003b)

30. Testamento de Rodrigo Peres (meados do século XIII. Martins 2001) 